\title{
Pearls for Floppy Iris Syndrome
}

\author{
Bryan Lee
}

Altos Eye Physicians, LOS Altos, CA, US

ntraoperative floppy iris syndrome (IFIS) increases the potential for problems during cataract surgery. Although most strongly associated with tamsulosin, cataract surgeons should be aware of other medications that may cause IFIS. Pharmacologic techniques such as intracameral phenylephrine or epinephrine can improve dilation and iris stability. Mechanical strategies include viscomydriasis and devices like iris hooks or the Malyugin Ring (MicroSurgical Technology, Inc., Redmond, WA, US). A careful history to elucidate patients' risk for IFIS may be the most important step of all, as surgeon preparedness is probably the most significant way to lower risk of complications.

\section{Keywords}

Intraoperative floppy iris syndrome, IFIS, small pupil, cataract surgery, cataract complications

Disclosure: Bryan Lee has nothing to disclose in relation to this article.

Review Process: This article is a short educational piece and has not been submitted to external peer reviewers, but was reviewed by the editorial board for accuracy before publication.

Authorship: All named authors meet the International Committee of Medical Journal Editors (ICMJE) criteria for authorship of this manuscript, take responsibility for the integrity of the work as a whole, and have given final approval to the version to be published.

open Access: This article is published under the Creative Commons Attribution Noncommercial License, which permits any noncommercial use, distribution, adaptation, and reproduction provided the original author(s) and source are given appropriate credit. (c) The Authors 2018.

Received: February 22, 2018

Published Online: March 26, 2018

Citation: US Ophthalmic Review, 2018;11(1):26-28

Corresponding Author: Bryan Lee, Altos Eye Physicians, 762 Altos Oaks Drive \#1, Los Altos, CA 94024, US.

E: bryan@bryanlee.pro

@bryanleemd

Support: No funding was received for the publication of this article.
Small pupils present a significant challenge for the cataract surgeon, requiring excellent intraoperative decision making to maximize the likelihood of a successful outcome. One of the common causes of small pupils, intraoperative floppy iris syndrome (IFIS), in particular increases the likelihood of complications such as posterior capsule rupture and iris trauma. Fortunately, a variety of pharmacologic and mechanical strategies are available to help maintain an adequately dilated pupil to increase the likelihood of successful, safe cataract surgery.

IFIS was first described in association with current or prior tamsulosin (Flomax ${ }^{\circledast}$, Boehringer Ingelheim, Ingelheim am Rhein, Germany; Ridgefield, CT, US) use in 2005. 'Besides poor preoperative pupil dilation, severe IFIS exhibits a triad of intraoperative signs: (1) iris billowing and floppiness, (2) iris prolapse to the incisions, and (3) progressive intraoperative miosis (Figure 1). However, there is a wide range of clinical severity. IFIS can be graded as mild (good dilation; some iris billowing without prolapse or constriction), moderate (iris billowing with some constriction of a moderately dilated pupil), or severe. ${ }^{2}$ In a prospective study of 167 eyes in patients taking tamsulosin, 10\% had no IFIS, 17\% mild IFIS, 30\% moderate IFIS, and $43 \%$ severe IFIS. ${ }^{2}$ Poor preoperative pupil dilation and iris billowing during instillation of intracameral lidocaine are predictive of greater IFIS severity. ${ }^{2-5}$ Numerous studies have confirmed that unexpected IFIS increases the rate of cataract surgical complications. ${ }^{2,3,6-9}$ A retrospective study of nearly 100,000 surgeries in male patients with cataracts reported a two-fold increase in the rate of serious postoperative complications including retinal detachment, retained nuclear fragments, and severe inflammation in patients taking tamsulosin. ${ }^{6}$

IFIS has since been documented with other systemic alpha-1 antagonists such as doxazosin (Cardura ${ }^{\circledR}$, Pfizer, New York, NY, US), terazosin (Hytrin ${ }^{\oplus}$, Abbott, Chicago, IL, US), and alfuzosin (Uroxatral ${ }^{\circledR}$, Sanofi Aventis, Paris, France), all of which are non-selective alpha-1 antagonists. ${ }^{3}$ A number of retrospective and prospective studies have also shown that the frequency and severity of IFIS is much higher with tamsulosin than non-selective alpha-1 antagonists. ${ }^{3,4,6-8,10,11}$ Silodosin (Rapaflo ${ }^{\circledast}$, Allergan, Irvine, CA, US) is a systemic selective alpha-1A blocker that is similar to tamsulosin in its strong propensity to cause IFIS. Ophthalmologists should also know that Jalyn ${ }^{\circledast}$ (GlaxoSmithKline, Brentford, UK) is the brand name for the combination of dutasteride and tamsulosin.

The surgeon should assess the quality of dilation during the presurgical examination, but a careful history is also important to reduce the likelihood of unexpected intraoperative miosis. In fact, even female patients are now treated with tamsulosin for urinary problems. ${ }^{12}$

Unfortunately, stopping tamsulosin preoperatively is of questionable value. ${ }^{2}$ Preoperative counseling with high-risk patients should occur to discuss the risk of IFIS and subsequent iris and pupil changes.

Intracameral injection of alpha agonists such as phenylephrine or epinephrine, as first reported by Gurbaxani \& Packard and Shugar, respectively, is a safe and inexpensive strategy for IFIS (Figure 2). ${ }^{13-15}$ Healon $5^{\circledast}$ (2.3\% sodium hyaluronate; Abbott Medical Optics, Santa Ana, CA, US) is a maximally 
Figure 1: Miosis and billowing associated with intraoperative floppy iris syndrome

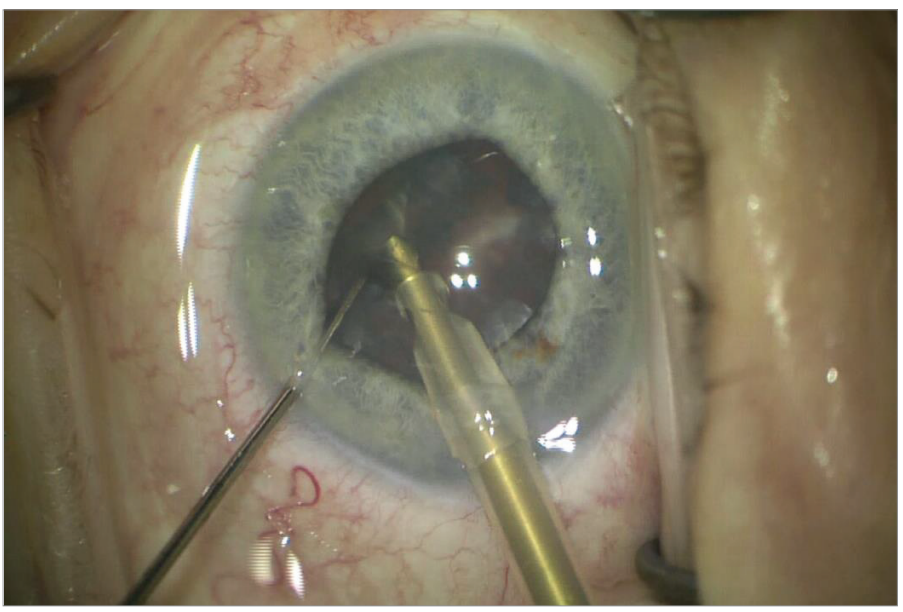

cohesive single agent that is particularly well suited for viscomydriasis and for blocking the iris from prolapsing in IFIS, as first suggested by Osher \& Koch. ${ }^{16}$ In the tamsulosin versus alfusosin study, moderate to severe IFIS was present in $12.4 \%$ of control eyes performed without epinephrine in the irrigating fluid, demonstrating for the first time the beneficial impact of having epinephrine in the irrigating fluid during phaco. ${ }^{5}$

Pupil expansion rings are disposable devices that mechanically expand and maintain the intraoperative pupil diameter. The semicircular Morcher $^{\circledR}$ 5S Pupil Dilator (FCl Ophthalmics, Pembroke, MA, US) and the Perfect Pupil ${ }^{\circledR}$ (Milvella, Savage, MN) are grooved polymethyl methacrylate (PMMA) rings. ${ }^{17,18}$ Alternatives include the APX $200(\mathrm{FCl}$ Ophthalmics, Pembroke, MA, US) and Graether pupil expander (Eagle Vision, Memphis, TN, US). ${ }^{19}$ All of these devices are relatively difficult to position if the pupil is less than $4 \mathrm{~mm}$ wide or if the anterior chamber is shallow. They will fail to engage the iris if the pupil diameter is larger than $7 \mathrm{~mm}$.

The Malyugin Ring ${ }^{\circledR}$ (Microsurgical Technology, Redmond, WA, US) is a 5-0 polypropylene single use device that is introduced with a disposable injector (Figure 3). ${ }^{20}$ The way in which the iris drapes over the sides of the device creates a round $6.25 \mathrm{~mm}$ or $7 \mathrm{~mm}$ pupil diameter. Compared to the bulkier plastic expansion rings the thinner profile of the Malyugin Ring reduces the risk of accidental corneal or incisional trauma and does not impede instrument access to the cataract. The Malyugin Ring may be preferred to iris hooks in the presence of a bleb, a pterygium, keratoconus, and radial keratotomy scars, and avoids the problem of iris hooks being pushed against the lid speculum with a tight palpebral fissure or uncooperative patient. The OASIS Iris Expander (OASIS Medical, San Dimas, CA, US) is a similar polypropylene device with four pockets instead of rings. Neither device can engage pupils dilated beyond $7 \mathrm{~mm}$, however.

Iris retractors provide sufficient tension to the iris stroma so that no prolapse can occur with IFIS (Figure 4). Maximal widening with iris retractors can be safely employed with IFIS eyes because of the elasticity of the pupil margin. Iris retractors are advantageous when a toric intraocular lens
Figure 2: Before and after injection of intracameral phenylephrine

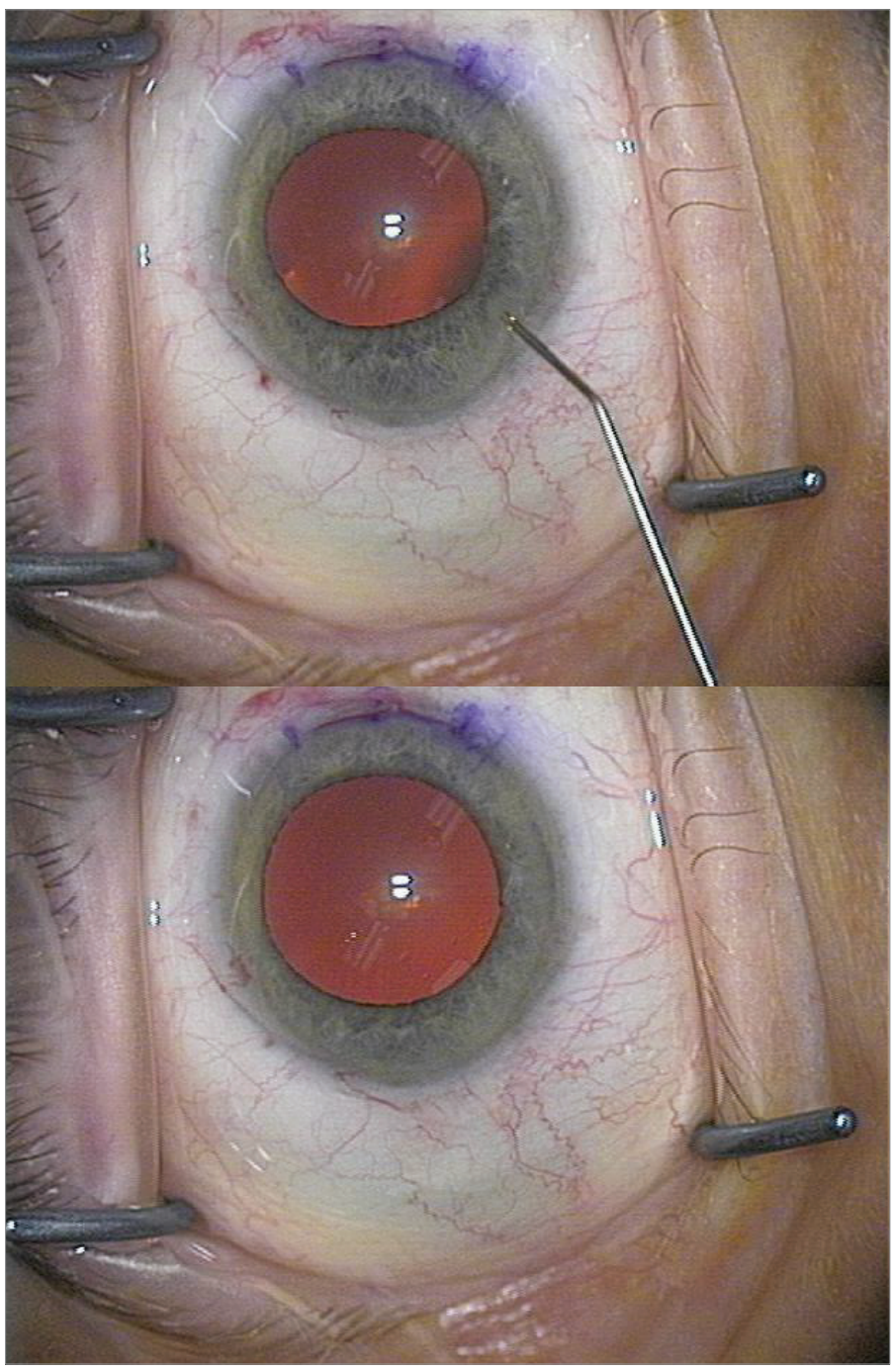

Figure 3: The Malyugin Ring

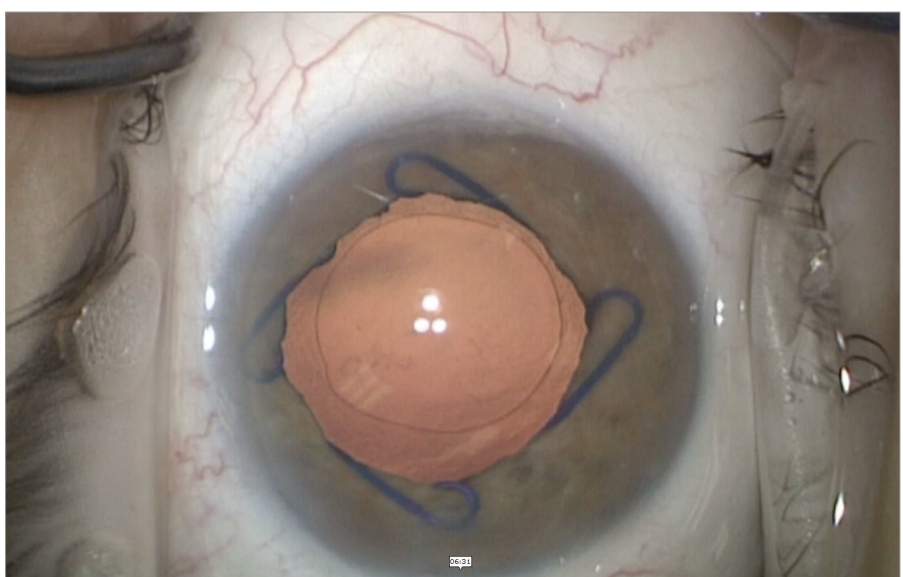

The Malyugin Ring ${ }^{\circledR}$ (Microsurgical Technology, Redmond, WA, US) comes in $6.25 \mathrm{~mm}$ and $7 \mathrm{~mm}$ sizes. 
Figure 4: Iris hooks being used to enlarge the pupil

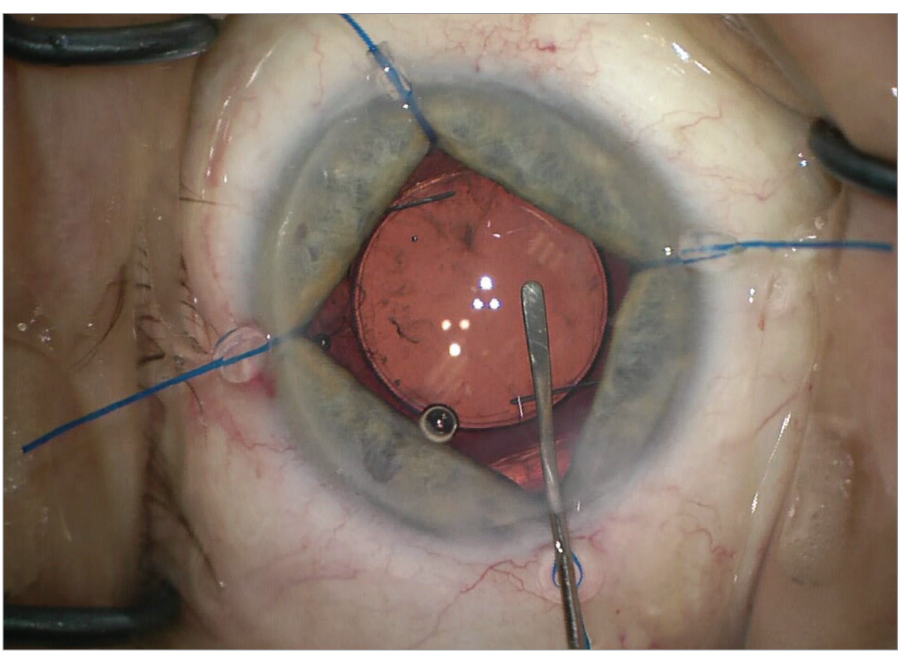

Iris hooks can be used to enlarge the pupil beyond $7 \mathrm{~mm}$, which can help control intraoperative floppy iris syndrome. Placing one of the hooks subincisionally can improve access through the wound.
(IOL) is used because two of the retractors can often be aligned with the astigmatic axis. A particular advantage of using iris retractors for cases with weak zonules is that the retractors can be readily repositioned around the capsulorrhexis edge to serve as capsule retractors if necessary. Reusable 4-0 polypropylene retractors (available from Katena Products, Inc., Denville, $\mathrm{NJ}$, US and $\mathrm{FCl}$ Ophthalmics) are much more cost effective than any other pupil expander, including disposable 6-0 nylon retractors (available from Alcon Laboratories, Inc., Fort Worth, TX, US). ${ }^{21}$ The greater rigidity makes 4-0 retractors more durable and easier to manipulate.

Before initiating the capsulorrhexis, $1 \mathrm{~mm}$ limbal paracenteses are created in each quadrant, including a separate stab incision just posterior to the temporal clear corneal incision in a diamond configuration as originally advocated by Oetting and Omphroy.22 Alternatively, a 25 or 26 gauge needle can be used to make tracts for the hooks. ${ }^{22,23}$

Use of tamsulosin continues to increase in the cataract population, but ophthalmologists can continue to deliver great results thanks to awareness of each patient's risk for IFIS and familiarity with a few of these surgical management techniques. $\square$
1. Chang DF, Campbell JR. Intraoperative floppy iris syndrome associated with tamsulosin (Flomax). J Cataract Refract surg. 2005;31:664-73.

2. Chang DF, Osher RH, Wang L, Koch DD. Prospective multicenter evaluation of cataract surgery in patients taking tamsulosin (Flomax). Ophthalmology. 2007;114:957-64.

3. Chang DF, Braga-Mele R, Mamalis N, Committee eaftACC. ASCRS white paper: intraoperative floppy iris syndrome - a clinical review. I Cataract Refract Surg. 2008;34:2153-62.

4. Chatziralli IP, Sergentanis TN. Risk factors for intraoperative floppy iris syndrome' a meta-analysis Ophthalmology. 2011:118:730-5.

5. Chang DF, Campbell JR, Colin J. Schweitzer for the Surgeon Study Group. Intraoperative floppy iris syndrome severity with tamsulosin versus alfusosin. Ophthalmology. 2014;121:829-34.

6. Bell CM, Hatch WW, Fischer HD, et al. Association between tamsulosin and serious ophthalmic adverse events in older men following cataract surgery. JAMA. 2009;301:1991-6.

7. Blouin $\mathrm{M}$, Blouin J, Perreault $\mathrm{S}$, et al. Intraoperative floppy iris syndrome associated with Alpha-1 adrenoreceptors. Comparison of tamsulosin and alfuzosin. I Cataract Refract Surg. 2007:33:1227-34.

8. Chadha V, Borooah S, Tey A, et al. Floppy iris behaviour during cataract surgery: associations and variations. Br J Ophthalmol. 2007:91:40-2
9. Chang DF, Braga-Mele R, Mamalis N, et al. Clinical experience with intraoperative floppy-iris syndrome. Results of the 2008 ASCRS member survey. J Cataract Refract Surg. 2008:34:1201-9.

10. Casuccio A, Cillino G, Pavone $\mathrm{C}$, et al. Pharmacologic pupil dilation as a predictive test for the risk of intraoperative floppy-iris syndrome. J Cataract Refract Surg. 2011;37:1447-54.

11. Palea S, Chang DF, Rekik M, et al. Comparative effect of alfuzosin and tamsulosin on the contractile response of isolated rabbit prostatic and iris dilator smooth muscles. Possible model for intraoperative floppy iris syndrome. J Cataract Refract Surg. 2008;34:489-96.

12. Chang SJ, Chiang IN, Yu HJ. The effectiveness of tamsulosin in treating women with voiding difficulty. Int J Urol. 2008:15: $981-5$

13. Gurbaxani A, Packard R. Intracameral phenylephrine to prevent floppy iris syndrome during cataract surgery in patients on tamsulosin. Eye. 2007;21:331-2.

14. Shugar JK. Intracameral epinephrine for prophylaxis of IFIS [letter]. J Cataract Refract Surg. 2006;32:1074-5.

15. Lorente R, de Rojas $\mathrm{V}$, Vázquez de Parga P, et al. Intracameral phenylephrine $1.5 \%$ for prophylaxis against intraoperative floppy iris syndrome: prospective, randomized fellow eye study. Ophthalmology. 2012;119:2053-8.
16. Chang DF. Intraoperative Floppy Iris Syndrome. In: Agarwal A Phaco Nightmares: Conquering Cataract Catastrophies, Thorofare NJ, US: SLACK Inc, 2006;134.

17. Akman A, Yilmaz G, Oto S, Akova Y. Comparison of various pupil dilatation methods for phacoemulsification in eyes with a small pupil secondary to pseudoexfolication. Ophthalmology. 2004;111:1693-8.

18. Kershner RM. Management of the small pupil for clear corneal cataract surgery. I Cataract Refract Surg. 2002;28:1826-31.

19. Graether JM. Graether pupil expander for managing the small pupil during surgery. J Cataract Refract Surg. 1996;22:530-5.

20. Chang DF. Use of Malyugin pupil expansion device for intraoperative floppy iris syndrome: Results in 30 consecutive cases. I Cataract Refract Surg. 2008;34:835-41.

21. Nichamin LD. Enlarging the pupil for cataract extraction using flexible nylon iris retractors. J Cataract Refract Surg. 1993;19:793-6.

22. Oetting TA, Omphroy LC. Modified technique using flexible iris retractors in clear corneal cataract surgery. I Cataract Refract Surg. 2002:28:596-8.

23. Dupps WJ, Oetting TA. Diamond iris retractor configuration for small-pupil extracapsular or intracapsular cataract surgery. J Cataract Refract Surg. 2004;30:2473-5. 